\title{
Original article \\ Critical stroke rate as a parameter for evaluation in swimming
}

\author{
Marcos Franken \\ Federal University of Rio Grande do Sul, Brazil \\ Fernando Diefenthaeler \\ Federal University of Santa Catarina, Brazil \\ Felipe Collares Moré \\ Federal University of Rio Grande do Sul, Brazil \\ Ricardo Peterson Silveira \\ University of Verona, Verona, Italy \\ Flávio Antônio de Souza Castro \\ Federal University of Rio Grande do Sul, Brazil
}

\begin{abstract}
The purpose of this study was to investigate the critical stroke rate (CSR) compared to the average stroke rate (SR) when swimming at the critical speed (CS). Ten competitive swimmers performed five $200 \mathrm{~m}$ trials at different velocities relative to their CS (90, 95, 100, 103 and 105\%) in front crawl. The CSR was significantly higher than the SR at $90 \%$ of the CS and lower at 105\% of the CS. Stroke length (SL) at 103 and $105 \%$ of the CS were lower than the SL at 90, 95, and 100\% of the CS. The combination of the CS and CSR concepts can be useful for improving both aerobic capacity/power and technique. CS and CSR could be used to reduce the SR and increase the SL, when swimming at the CS pace, or to increase the swimming speed when swimming at the CSR.
\end{abstract}

Keywords: stroke parameters, training control, critical swimming speed, front crawl

Resumo-_"Frequência critica de braçadas como parâmetro para avaliação em natação." O objetivo deste estudo foi investigar a frequência crítica de braçadas (FCB) comparando com a frequência de braçadas (FB) quando nadando na velocidade crítica (VC) e em diferentes percentuais da VC no nado crawl. Dez nadadores competitivos realizaram repetições máximas nas distâncias de 200 e 400 m para a determinação da VC e FCB. Posteriormente, os sujeitos realizaram cinco repetições de $200 \mathrm{~m}$ a 90, 95, 100, 103 e 105\% da VC, em ordem aleatória. FCB foi significativamente maior do que FC obtida a $90 \%$ e menor do que obtida a $105 \%$ da VC. Comprimento de braçada (CB) a $103 \%$ e $105 \%$ da VC foi menor quando comparado às repetições a 90, 95 e 100\% da VC. A combinação dos conceitos de VC e FCB pode ser útil para incremento de ambos, capacidade/potência aeróbia e técnica, com objetivo de reduzir FB (e incrementar $\mathrm{CB}$ ) quando nadando no ritmo de $\mathrm{VC}$ ou incrementar a velocidade de nado utilizando-se a FCB.

Palavras-chaves: parâmetros de braçada, controle do treinamento, velocidade crítica em natação, nado crawl

Resumen-“Frecuencia crítica de brazada como parámetro para evaluación en la natación." El objetivo de este estudio fue investigar la frecuencia crítica de brazadas (FCB) en comparación con la frecuencia de brazadas (FB) al nadar a la velocidad crítica (VC) y diferentes porcentajes de la VC en estilo crol. Diez nadadores realizaron repeticiones máximas a distancias de 200 y $400 \mathrm{~m}$ para obtener la VC y la FCB. Posteriormente, los sujetos realizaron cinco repeticiones a $200 \mathrm{~m}$ para 90, 95, 100, 103 y $105 \%$ de la VC, de forma aleatoria. LaFCB fue significativamente mayor que la FC obtenida a $90 \%$ y menor que la FC obtenida a $105 \%$ de la VC. La longitud de la brazada (LB) a $103 \%$ y $105 \%$ de la VC fue menor en comparación con las repeticiones al 90, 95 y $100 \%$ de la VC. La combinación de los conceptos de VC y FCB puede ser útil para aumentar tanto la capacidad / potencia aerobio y la técnica destinada a reducir la FB (y aumentar LB) al nadar en el ritmo de la VC o aumentar la velocidad de nado con la FCB.

Palabras claves: parámetros de brazadas, control del entrenamiento, velocidad crítica en natación, crol 


\section{Introduction}

The adapted concept of critical speed, as suggested by Hill and Ferguson (1999) and Wakayoshi et al. (1992), has been widely assessed in sports when measurements of power output are difficult (i.e. running and swimming). The critical swimming speed (CS) elicits an intensity greater than the anaerobic threshold (Dekerle, Brickley, Alberty, \& Pelayo, 2010). It is a non-invasive and practical method for training control and prescription in cyclic sports (Jenkins \& Quigley, 1990; Poole, Ward, Gardner, \& Whipp, 1988; Soares-Caldeira et al., 2012). One way to measure the CS is through the slope of the distance-time relationship, gathered from a linear regression of performance data from two or more distances. These should cover durations between 2 and 15 min (Pelayo, Alberty, Sidney, Potdevin, \& Dekerle., 2007). Hill and Ferguson (1999) described CS as the maximum speed that could be sustained without eliciting maximum oxygen uptake, at constant speed, representing the transition between the heavy and the severe intensities (Dekerle et al., 2010; Espada \& Alves, 2010; Franken, Zacca \& Castro, 2011; Ribeiro, Lima \& Gobatto, 2010).

Regarding the studies related to the CS in swimming, increases in blood lactate concentration, heart rate, and perceived exertion were observed when well-trained swimmers performed five repetitions of $400 \mathrm{~m}$ at the CS (Ribeiro et al., 2010). However, Dekerle et al. (2010) evaluated nine competitive swimmers and observed no significant changes in blood lactate concentration but increases in perceived exertion during 10 repetitions of $400 \mathrm{~m}$ at the CS. Swimming velocity depends on the average stroke rate (SR) and stroke length (SL) (Craig \& Pendergast, 1979; Smith, Norris, \& Hogg, 2002). Therefore, in order to sustain a given speed, swimmers generally use a combination of SR and SL which they consider to be the most efficient (Dekerle et al., 2005). Ribeiro et al. (2010) evaluated competitive swimmers performing five repetitions of $400 \mathrm{~m}$ at the CS, with $90 \mathrm{~s}$ of passive rest, and observed increases in SR and decreases in SL. According to the authors, swimmers adopted this strategy to maintain swimming speed throughout the test (Dekerle et al., 2005; Yanai, 2003). On the other hand, Dekerle, Sidney, Hespel, \& Pelayo (2002) compared competitive swimmers at the CS and at the maximal speed archived during a 30 min test and observed no significant differences in SR. Dekerle et al. (2005) assessed kinematics (swimming speed, SR and SL) of 11 well-trained swimmers at different intensities $(75,80,85$, and $90 \%$ of the maximal aerobic speed estimated from an all-out $400 \mathrm{~m}$ front crawl test) and observed an increase in SR and a decrease in SL at intensities greater than the maximal lactate stead state. The decrease in SL can be linked to muscular fatigue, which may have reduced propulsive force and, consequently, swimming speed. In attempt to maintain swimming velocity at intensities above maximal lactate steady state, swimmers increase SR due to shorter SL (Schnitzler, Seifert, \& Chollet, 2009).

Therefore, changes in the SR are expected to maintain swimming speed at intensities close to the CS during interval training sets. Dekerle et al., (2002) and Dekerle (2006) proposed the critical stroke rate (CSR) method, defined as the highest SR that could be maintained indefinitely. It is computed by the slope of the relationship between the number of stroke cycles and time using the same trials used to obtain the CS. In swimming training, intensity and technique control are very important parameters for monitoring training program. Given the CSR method has not been clearly assessed and considering its potential for training monitoring, the aim of the present study was to investigate CSR concept, comparing to the stroke rate at different percentages of the CS in front crawl. Our hypothesis was that the critical speed rate would be similar to the chosen SR when swimming at the CS. Once the hypothesis is confirmed, CSR could be used as a useful and easy intensity and technique control parameter along with CS in swimming training.

\section{Methods}

\section{Participants}

Ten well-trained male swimmers of local and national level (age: $19.4 \pm 2.2$ years; height: $173.9 \pm 4.5 \mathrm{~cm}$; upper limbs span: $180.3 \pm 4.5 \mathrm{~cm}$; body mass: $64.7 \pm 7.1 \mathrm{~kg}$ ) with a minimum of six years of experience in swimming training and competition participated in the study. Swimmers trained six to eight sessions per week, covering from $30 \mathrm{~km}$ to $40 \mathrm{~km} /$ week, and most of the distance was covered under aerobic intensities. No dry land training was performed by the subjects during data collection. Recent competitive best time on $400 \mathrm{~m}$ front crawl was provided by the participants $(271.5$ $\pm 12 \mathrm{~s}, \sim 80 \%$ of the world record at that time). Prior to the protocol, all subjects were informed about the procedures and signed an informed consent document to participate in the study, which was approved by the Committee of Ethics in Research with Humans of the university where this study was conducted (2007887).

\section{Protocol}

Swimmers were asked to refrain from any high-intensity or exhaustive exercise at least 24 hours before the trials. The protocol was performed in a $25 \mathrm{~m}$ indoor swimming pool (water temperature $28-30^{\circ} \mathrm{C}$ ) and the front crawl stroke technique was adopted for all trials. After swimming warmup of 800 to $1000 \mathrm{~m}$ at low intensity front crawl, subjects performed, in random order, two maximal swimming trials (200 and $400 \mathrm{~m}$ ), separated by an interval of 48 hours. Then, 48 hours after the last maximal trial, swimmers performed five sets of $200 \mathrm{~m}$ trials at different speeds relative to their CS (90, 95, 100, 103, and $105 \%$ of the CS for measurements of mean SR and SL for each trial. The order was randomized and a $90 \mathrm{~s}$ of passive rest inside the pool was enforced. 


\section{Stroke parameters}

To determine stroke parameters for all trials, a $10 \mathrm{~m}$ sector was defined in the center of the swimming pool to minimize the effects of swimmer's impulse from the wall. During every $50 \mathrm{~m}$, two trained researchers recorded the time to perform $10 \mathrm{~m}$ and the time to perform three complete arm stroke cycles (one stroke cycle was considered as the time gap between two consecutives entries of the right hand in the water) using chronometers (Technos, 100 lap memory model, Switzerland). SR was obtained using the time to perform one complete arm stroke cycle, considering the time to perform three arm strokes cycles (T3C) at the $10 \mathrm{~m}$ zone, as described in the Equation

$$
S R=\left(t_{\text {stroke }}^{-1}\right) \times 60
$$

1.

Equation 1.SR represents the stroke rate and $t_{\text {stroke }}$ is the average time to perform on complete arm stroke.

The average SV was measured during each $10 \mathrm{~m}$ section,

$$
S V=\Delta d / \Delta t
$$

as described in the Equation 2.

Equation 2. SV is the average swimming speed, $\Delta \mathrm{d}$ represents the distance in the $10 \mathrm{~m}$ section and $t$ is the time to perform $10 \mathrm{~m}\left(\mathrm{~T}_{10}\right)$. SL was determined by the ratio

$$
S L=\frac{S V}{\left(S R \times 60^{-1}\right)}
$$

between the average SV and SR, as described in Equation 3.

Equation 3. S1 is the stroke length (m), Sv the swimming velocity $\left(\mathrm{m} \cdot \mathrm{s}^{-1}\right)$ and $\mathrm{Sr}$ the stroke rate $\left(\right.$ cycles. $\left.\mathrm{min}^{-1}\right)$.

\section{Critical speed (CS) and critical stroke rate (CSR)}

$$
C S=\frac{d_{400}-d_{200}}{t_{400}-t_{200}}
$$

Performances of both tests (200 and $400 \mathrm{~m}$ ) were used to calculate individual CS based on the Equation 4:

Equation 4. CS is the critical speed $\left(\mathrm{m} \cdot \mathrm{s}^{-1}\right), \mathrm{d}_{400}$ and $\mathrm{d}_{200}$ are the distances in each maximal test $(\mathrm{m}), \mathrm{t}_{400}$ and $\mathrm{t}_{200}$ are the times to perform each maximal test (s).

Through the average SR values, it was possible to

$$
n_{x}=S R_{x} \cdot t_{x} / 60
$$

estimate the total number of arm stroke cycles performed during each maximal test, as described in the Equation 5.

Equation $5 . \mathrm{n}_{\mathrm{x}}$ is the number of strokes, $\mathrm{SR}_{\mathrm{x}}$ is the stroke rate and $t_{x}$ is the time to perform the maximal test. The CSR has been obtained using the estimated number of arm

$$
C S R=\frac{n_{400}-n_{200}}{\left(t_{400}-t_{200}\right) \cdot 60^{-1}}
$$

strokes performed during both maximal tests, as described in the following Equation 6:

Equation 6. CSR is the critical stroke rate (cycles.min $\left.{ }^{1}\right), \mathrm{n}_{400}$ and $\mathrm{n}_{200}$ are the distances, and $\mathrm{t}_{400}$ and $\mathrm{t}_{200}$ are the times to perform 400 and $200 \mathrm{~m}$.

\section{Swimming test based on different percents of the critical speed}

Swimmers performed five sets of $200 \mathrm{~m}$ at different percentages of their Cs (PSV). Total time (T200), T10 and $\mathrm{T} 3 \mathrm{C}$ in each repetition were recorded and used to calculate mean SV, SR, and SL. For all trials the pace was controlled by sonorous signals and visual warnings, in attempt to minimize the difference between actual and prescribed time. An error of $\pm 2.5 \%$ was accepted among trials (Seifert et al., 2004).

\section{Statistical analysis}

All data were reported as mean and standard-deviation. Data normality and sphericity were confirmed by ShapiroWilk's and Mauchly's tests, respectively. Student $t$-tests were used to compare, at each \%Cs i) CSR and SR (both expressed in cycles $\cdot \mathrm{min}^{-1}$ ) at different percents of the CS and ii) PSV and SV (both expressed in $\mathrm{m} \cdot \mathrm{s}^{-1}$ ). When differences between PSV and SV were observed, SV was compared with the above \%CS. Reliability of the SR measurements, among the different \%CS, was analyzed with the application of the intraclass correlation coefficient (ICC), with a confidence interval of 95\%. SV (expressed in \%CS), SR (expressed in \%CSR), and SL (expressed in $\mathrm{m})$ were compared among the different \%Cs with ANOVA for repeated measures. Bonferroni tests were used to identify the differences. When necessary, GreenhouseGeisser's Epsilon correction factors were used (indicated by the degrees of freedom). Eta ${ }^{2}$ and observed power were calculated. The statistical analyses were performed using SPSS 12.0 (SPSS Inc., USA). A significance level of 0.05 was adopted for all tests.

\section{Results}

Table 1 shows mean values of stroke rate at $200 \mathrm{~m}$ $\left(\mathrm{SR}_{200}\right)$ and $400 \mathrm{~m}\left(\mathrm{SR}_{400}\right)$, total time for $200 \mathrm{~m}\left(\mathrm{Tt}_{200}\right)$ and $400 \mathrm{~m}\left(\mathrm{Tt}_{400}\right)$, and critical speed (CS) expressed in $\mathrm{m} \cdot \mathrm{s}^{-1}$. 
Table 1. Mean and standard-deviation for stroke rate at $200 \mathrm{~m}\left(\mathrm{SR}_{200}\right)$ and $400 \mathrm{~m}\left(\mathrm{SR}_{400}\right)$, total time for $200 \mathrm{~m}\left(\mathrm{Tt}_{200}\right)$ e $400 \mathrm{~m}\left(\mathrm{Tt}_{400}\right)$ and critical speed $(\mathrm{CS})(\mathrm{n}=10)$.

\begin{tabular}{cccccc}
\hline & $\begin{array}{c}\mathrm{SR}_{200} \\
\left(\text { cycles} \cdot \mathrm{min}^{-1}\right)\end{array}$ & $\begin{array}{c}\mathrm{SR}_{400} \\
\left(\text { cycles} \cdot \mathrm{min}^{-1}\right)\end{array}$ & $\begin{array}{c}\mathrm{Tt}_{200} \\
(\mathrm{~s})\end{array}$ & $\begin{array}{c}\mathrm{Tt}_{400} \\
(\mathrm{~s})\end{array}$ & $\begin{array}{c}\mathrm{CS} \\
\left(\mathrm{m} \cdot \mathrm{s}^{-1}\right)\end{array}$ \\
\hline Mean & 41.03 & 36.48 & 140.84 & 303.03 & 1.24 \\
$\mathrm{SD}$ & 4.77 & 5.16 & 4.02 & 10.12 & 0.11 \\
\hline
\end{tabular}

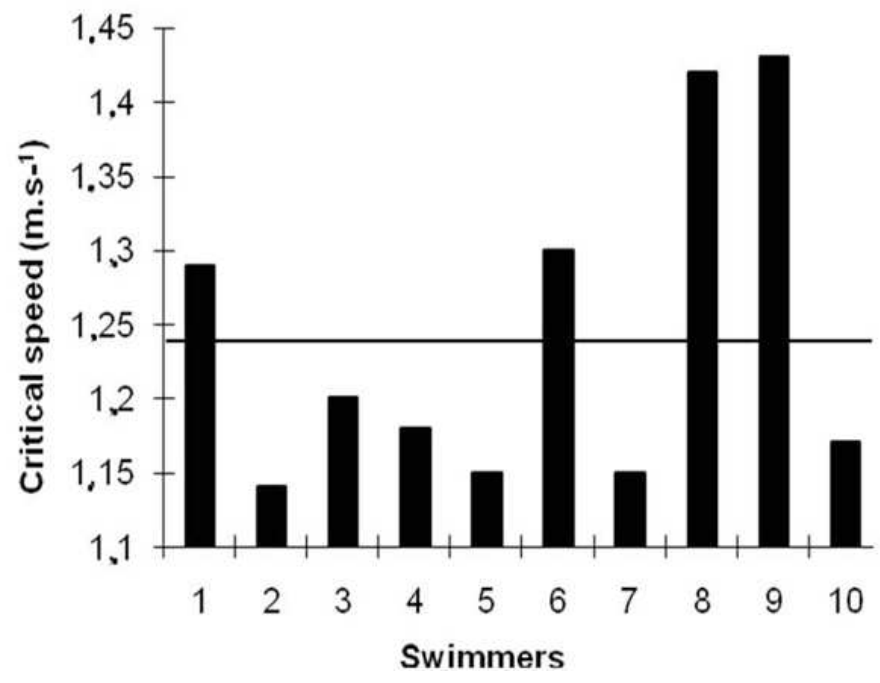

Figure 1. Individual critical speed compared to mean group critical speed.

$\mathrm{Tt}_{400}$ was $88.2 \%$ of the best $400 \mathrm{~m}$ front crawl recorded in competition. Figure 1 shows individual and the mean group results for $\mathrm{CS}$.

Significant differences occurred at 90, 95 and 100\%CS when compared to SV and between percents immediately above (which were 95, 100 and $103 \%$, respectively), indicating that swimmers were able to achieve the prescribed velocities during tests (Seifert et al., 2004).

Table 2 shows the comparison between CSR and SR at different percentages of the CS. Mean swimming speed related to each percentage of the CS are presented.

Significant differences between CSR and SR were observed only for 90 and $105 \%$ of the CS $(p<0.05)$. Mean value of the CSR $\left(32.42 \pm 3.77\right.$ cycles. min $\left.^{-1}\right)$ was $100.52 \pm$ $5.08 \%$ of the SR at $100 \%$ of the CS $\left(32.25 \pm 5.91\right.$ cycles.min $\left.^{-1}\right)$. Regarding the reliability of SR, ICC was 0.99 (confidence interval $\left.=0.852 ; 0.983 ; F_{9,36}=16.812 ; p<0.01\right)$.

Table 3 presents mean and standard-deviation and comparisons of SV (expressed in \%CS), SR (expressed in $\% \mathrm{CSR}$ ), and SL (expressed in $\mathrm{m}$ ) of the different \%CS trials.

Significant differences were found for SV among all the $\% \mathrm{CS}\left(F_{436}=274.1 ; p \leq 0.001 ; \eta^{2}=0.96\right.$; observed power: 1.00). When SR values, expressed in \%CSR, were
Table 2. Comparison between mean stroke rate (SR) at prescribed swimming velocity (PSV) and critical stroke rate (CSR). This table shows corresponding SV to each PSV ( $\mathrm{n}=10)$.

\begin{tabular}{ccc}
\hline PSV & SR $\left(\right.$ cycles $\left.\cdot \mathrm{min}^{-1}\right)$ & SV $\left(\mathrm{m} \cdot \mathrm{s}^{-1}\right)$ \\
\hline $90 \% \mathrm{CS}$ & $27.84(3.52)^{*}$ & $1.14(0.03)$ \\
$95 \% \mathrm{CS}$ & $30.29(3.49)$ & $1.20(0.05)$ \\
$100 \% \mathrm{CS}$ & $32.25(5.91)$ & $1.25(0.03)$ \\
$103 \% \mathrm{CS}$ & $34.90(5.49)$ & $1.28(0.04)$ \\
$105 \% \mathrm{CS}$ & $36.84(5.70)^{*}$ & $1.31(0.05)$ \\
CSR & $32.42(3.70)$ & - \\
\hline *significant difference $(p<0.05)$ comparing to CSR.
\end{tabular}

compared, differences were found to all \% CS $\left(\mathrm{F}_{4,36}=\right.$ 26,$163 ; p \leq 0.001 ; \eta^{2}=0.74$; observed power: 1.00$)$. Significant differences were found for SL $\left(\mathrm{F}_{4,36}=4.75 ; p=\right.$ $0.004 ; \eta^{2}=0.34$; observed power: 0.923$)$ SL at 103 and $105 \%$ of the CS were lower than the SL at 90, 95, and $100 \%$ of the CS. However, SL showed significant difference only at 103 and $105 \%$ of the CS. SL presented significant difference at intensities greater than the CS.

\section{Discussion}

The aim of the present study was to compare CSR to the SR observed in different intensities of the CS, to properly explore the use of the CSR as a tool for intensity and technique control combined to the CS in swimming training. During the $200 \mathrm{~m}$ repetitions, significant differences were observed between CSR and SR at intensities corresponding to 90 and $105 \%$ of the CS. But when swimming at intensities corresponding to 95,100 , and $103 \%$ of the CS, the SR was similar to the CSR, partially confirming the hypothesis of the present study (critical speed rate would be similar to SR adopted when swimming at CS).

Dekerle et al. (2002) defined CSR as the SR that could be maintained for a long period of time without exhaustion. If $\mathrm{CS}$ is defined as the highest intensity sustainable for a long period of time without reaching maximal oxygen uptake, at a constant workload (Hill \& Ferguson, 1999), when both parameters (CS and CSR) are selected, swimming intensity would be sustained maintaining a "critical" stroke length ( swimming velocity $=$ SR $x$ SL).

CSR was suggested by Dekerle et al. (2006) to be used simultaneously to the CS to control training intensity and technique. As an example, CS should be controlled followed by lowering the SR than the CSR, or maintaining the CSR while swimming faster than the CS. According to Dekerle et al. (2006) swimmers would opt for a greater SL at CS as a result of training.

Increases in SR followed by increases in swimming speed observed in the present study are consistent with other studies (Craig \& Pendergast, 1979; Smith et al., 2002; Yanai, 2003). According to these authors, increases in swimming speed are due to an increase in SR with simultaneous decrease in SL. Wakayoshi, Yoshida, Ikuto, Mutoh and 
Table 3. Comparison of swimming velocity (SV - \% of the critical speed - \%CS), stroke rate (SR - \% of the critical stroke rate - CSR) and stroke length (SL - in $\mathrm{m}$ ) among the $200 \mathrm{~m}$ trials (percentage values of the real critical speed) (90 to $105 \% \mathrm{CS})(\mathrm{n}=10)$.

\begin{tabular}{cccccc}
\hline & $90 \% \mathrm{CS}$ & $95 \% \mathrm{CS}$ & $100 \% \mathrm{CS}$ & $103 \% \mathrm{CS}$ & $105 \% \mathrm{CS}$ \\
\hline $\begin{array}{c}\mathrm{SV} \\
(\% \mathrm{CS})\end{array}$ & $91.53 \pm 0.96^{\mathrm{b}, \mathrm{c}, \mathrm{d}, \mathrm{e}}$ & $96.07 \pm 1.33^{\mathrm{c}, \mathrm{d}, \mathrm{e}}$ & $100.83 \pm 1.46^{\mathrm{d}, \mathrm{e}}$ & $103.80 \pm 1,41^{\mathrm{e}}$ & $105.95 \pm 1.44$ \\
$\begin{array}{c}\text { SR } \\
(\% \mathrm{CSR})\end{array}$ & $85.87 \pm 9.89^{\mathrm{b}, \mathrm{c,de}}$ & $93.42 \pm 10.90^{\mathrm{c}, \mathrm{d}, \mathrm{e}}$ & $99.47 \pm 18.73^{\mathrm{d}, \mathrm{e}}$ & $107.64 \pm 16,32^{\mathrm{e}}$ & $113.63 \pm 18.04$ \\
$\begin{array}{c}\mathrm{SL} \\
(\mathrm{m})\end{array}$ & $2.27 \pm 0.31^{\mathrm{d}, \mathrm{e}}$ & $2.19 \pm 0.24^{\mathrm{d}, \mathrm{e}}$ & $2.15 \pm 0.22^{\mathrm{d}, \mathrm{e}}$ & $2.01 \pm 0.20^{\mathrm{e}}$ & $1.97 \pm 0.19$ \\
\hline
\end{tabular}

${ }^{b}$ Significant difference comparing trials at $95 \% \mathrm{Cs}$; ${ }^{\mathrm{c}}$ significant difference comparing trials at $100 \% \mathrm{CS}$.

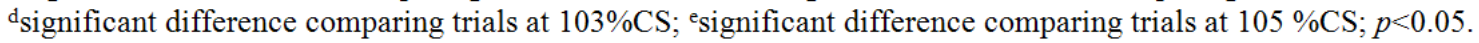

Miyashita (1993) and Yanai (2003) suggested that swimmers may increase SR as a strategy to increase velocity which may be a neuromuscular adaptation to accommodate greater a swimming intensity.

In the present study significant differences were observed for SL only between 103 and $105 \%$ of the critical speed. However, shorter SL, as found at speed greater than the CS (see Table 3), could overload the neuromuscular system. That could lead to an increase in SR to sustain a similar swimming speed (Craig \& Pendergast, 1979). Our results are consistent with two others studies that found decreases in SL throughout a test at intensities above the maximal steady state of lactate (Dekerle et al., 2005) and above the CS (Barden \& Kell, 2009).

CSR and SR at 95, 100, and $103 \%$ of the CS were similar (Table 3). These results support the use of the CSR method, associated to the CS, as a useful tool for control training intensity and swimming technique. Five $200 \mathrm{~m}$ repetitions at $90,95,100,103$, and $105 \%$ of the CS, with 90 s of passive rest, induced an increase in SR as intensity increase.

High reliability of SR was found ( ICC $=0.99)$, suggesting a consistence of this variable among the $200 \mathrm{~m}$ trials. This indicates that the swimmers presented the same SR behavior throughout the set (i.e., swimmer with the lower stroke rate at $90 \%$ of the CS performed each repetition with the lower SR). More studies should be conducted to incorporate CSR method as a complementary parameter for CS to evaluate training effects and responses due to different swimming intensities (i.e. heavy intensity domain of the exercise) or longer series of aerobic and anaerobic training. Thus, the hypothesis of this study, which was that the CSR would be similar to the SR used when swimming at the CS, was partially confirmed. Our results did not show differences between the CSR and the SR at 95 and $103 \%$ of the CS. That probably occurred due to the short duration of the test and the interval training under random intensity protocol used. Monitoring this variable allows to identify possible training effects and to improve technique during training and competition. After a period of training, it is possible to evaluate the adaptations on technique by observing the relationship between the CS and the CSR, considering seeking for a possible "critical stroke length." However, during longer duration exercises at intensities close to the CS that is not expected to occur because the effort duration may lead the swimmer to opt for most economical SR, since that high SR values are correlated to high energy cost values (Dekerle et al., 2005). Therefore, it becomes necessary to evaluate this relationship during long swimming series.

\section{Conclusions}

The chosen SR was similar to the CSR when swimming at intensities corresponding to 95,100 , and $103 \%$ of CS. This finding suggests that using this simple method, coaches can easily gather CSR and use that as an additional parameter to control intensity and technique in swimmers training program.

Coaches may properly control exercise effort and technique during their training sessions by controlling pace and SR based on the CS and the CSR instead of controlling swimming time, as usually done in swimming training. The combination of the CS and CSR concepts can be useful for improving both aerobic capacity/power and technique, with focus on the reduction of the SR (and increase the SL) when swimming at the CS speed or to increase the swimming speed when swimming at the CSR.

\section{References}

Barden, J. M. \& Kell, R. T. (2009). Relationships between stroke parameters and critical swimming speed in a sprint interval training set. Journal of Sport Sciences, 27(3), 227-235. doi: 10.1080/02640410802475205

Craig, J. R. A. B. \& Pendergast, D. R. (1979) Relationships of stroke rate, distance per stroke and velocity in competitive swimming. Medicine and Science in Sports, 11(3), 278-83. Retrieved from http://www.teamtermin.com/docs/ Relationships_of_Stroke_Rate_Velocity_and_Distance_Per_Stroke_ Pendergast_Craig_1976.pdf

Dekerle, J., Sidney, M., Hespel J. M. \& Pelayo, P (2002) Validity and reliability of critical speed, critical stroke rate, and anaerobic capacity in relation to front crawl swimming performances. 
International Journal Sports Medicine, 23, 93-8. doi: 10.1055/ s-2002-20125

Dekerle, J., Nesi, X., Lefevre, T., Depretz, S., Sidney, M., Marchand, F. H., \& Pelayo, P. (2005). Stroking parameters in front crawl swimming and maximal lactate steady state speed. International Journal of Sports Medicine, 26, 53 -58. doi: 10.1055/s-2004817854

Dekerle, J. (2006). Application of the critical power concept in swimming? Portuguese Journal Sport Sciences, 6(2), 121-4. Retrieved from http://www.fade.up.pt/rpcd/_arquivo/ RPCD_vol.6_supl.2.pdf

Dekerle, J., Brickley, G., Alberty, M. \& Pelayo, P. (2010). Characterising the slope of the distance-time relationship in swimming. Journal of Science and Medicine in Sport, 13, 365370. doi: 10.1016/j.jsams.2009.05.007

Espada, M. A. \& Alves, F. B. (2010). Critical Velocity and the Velocity at Maximal Lactate Steady State in Swimming. In: Biomechanics and Medicine in Swimming XI. Oslo, 194-196.

Franken, M., Zacca, R. \& Castro, F. A. S. (2011). Velocidade crítica em natação: fundamentos e aplicação. Revista Motriz, 17(1), 209-222. Retrieved from http://dx.doi.org/10.5016/ 1980-6574.2011v17n1p209

Hill, D. W. \& Ferguson, C. S. (1999). A physiological description of critical velocity. European Journal of Applied Physiology, 79(3), 290-3. Retrieved from http://www.ncbi.nlm.nih.gov/ pubmed/10048636

Jenkins, D. G. \& Quigley, B. M. (1990). Blood lactate in trained cyclists during cycle ergometry at critical power. European Journal of Applied Physiology, 61, 278-283. Retrieved from http://www.springerlink.com/content/u387718067074782/

Pelayo, P., Alberty, M., Sidney, M., Potdevin, F. \& Dekerle, J. (2007). Aerobic potential, stroke parameters, and coordination in swimming front-crawl performance. International Journal of Sports Physiology and Performance, 2(4), 347-59. Retrieved from http://journals.humankinetics.com/ijspp-back-issues/ ijsppvolume 2 is sue 4 december/aerobicpotentialst rokeparametersandcoordinationinswimmingfrontcrawl performance

Poole, D. C., Ward, S. A., Gardner, G. W. \& Whipp, B. J. (1988). A metabolic and respiratory profile for prolonged exercise in man. Ergonomics, 31(9), 1265-1279.

Ribeiro, L. F. P. R., Lima, M. C. S. \& Gobatto, C. A. (2010). Changes in physiological and stroking parameters during interval swims at the slope of the d-t relationship. Journal of Science and Medicine in Sport, 13(1), 141-145. doi: 10.1016/ j.jsams.2008.10.001

Schnitzler, C., Seifert, L. \& Chollet, D. (2009). Variability of coordination parameters at 400-m front crawl swimming pace. Journal of Sports Science and Medicine, 8, 203-210. Retrieved from http://www.jssm.org/vol8/n2/6/v8n2-6abst.php

Seifert, L., Chollet, D. \& Bardy, B. G. (2004). Effect of swimming velocity on arm coordination in the front crawl: a dynamic analysis. Journal of Sports Sciences, 22, 651-660. doi: 10.1080/ 02640410310001655787

Smith, D., Norris, S. \& Hogg, J. (2002). Performance Evaluation of Swimmers. Scientific Tools. Sports Medicine, 32(9), 539554. Retrieved from http://www.ingentaconnect.com/content/ adis/smd/2002/00000032/00000009/art00001.

Soares-Caldeira, L. F., Okuno, N. M., Sales M. M., Campbell, C. S. G., Simões, H. G. \& Nakamura, F. Y. (2012). Similarity in physiological and perceived exertion responses to exercise at continuous and intermittent critical power. European Journal of Aplied Physiology, 112, 1637-1644. Retrieved from http:// www.ncbi.nlm.nih.gov/pubmed/21874553
Wakayoshi, K., Ikuta, K., Yoshida, T., Udo, M., Moritani, T., Mutoh, Y. \& Miyashita, M. (1992). Determination and validity of critical velocity as an index of swimming performance in the competitive swimmer. European Journal of Applied Physiology, 64, 153-157. Retrieved from http://dx.doi.org/10.1007/ BF00717953

Wakayoshi, K., Yoshida, T., Ikuto, Y., Mutoh, Y. \& Miyashita, M. (1993). Does critical swimming velocity represent exercise intensity at maximal lactate steady state? European Journal of Applied Physiology, 66, 90-95. Retrieved from http:// www.springerlink.com/content/u24137m4h4343423/

Yanai, T. (2003) Stroke frequency in front crawl: its mechanical link to the fluid forces required in non-propulsive directions. Journal of Biomechanics, 36(1), 53-62. doi: 10.1016/S00219290(02)00299-3

\section{Authors' note}

Marcos Franken, Felipe Collares Moré and Flávio Antônio de Souza Castro are affiliated with the Exercise Research Laboratory, Federal University of Rio Grande do Sul, Porto Alegre, Rio Grande do Sul, Brazil

Fernando Diefenthaeler is affiliated with the Biomechanics Laboratory, Federal University of Santa Catarina, Florianopolis, Santa Catarina, Brazil

Ricardo Peterson Silveira is affiliated with the Department of Neurological, Neuropsychological, Morphological and Movement Sciences, University of Verona, Verona, Italy.

\section{Acknowledgments}

We would like to thank CNPq for the research grant awarded to this study.

\section{Correspondence to:}

Marcos Franken

Escola de Educação Física - Laboratório de Pesquisa do Exercício Universidade Federal do Rio Grande do Sul

Rua Felizardo 750 - Jardim Botânico - Porto Alegre, RS 90690-200 Phone: +55 5133085859

E-mail: marcos_franken@yahoo.com.br

Manuscript received on April 21, 2012

Manuscript accepted on May 16, 2013

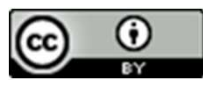

Motriz. Journal of Physical Education. UNESP, Rio Claro, SP, Brazil, eISSN: 1980-6574, is licenced under a Creative Commons License, Version 3.0. 